DE

M E D I C I N A

T R O P I C A L

$\mathrm{DE}$

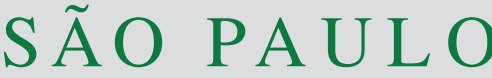

JOURNAL OF THE SÃO PAULO INSTITUTE OF TROPICAL MEDICINE

(1) Universidad Técnica Particular de Loja, Departamento de Ciencias de la Salud, sección de Genética Humana, Microbiología y Bioquímica Clínica, Loja, Equador

(2)Universidad Austral de Chile, Instituto de Microbiología Clínica, Valdívia, Región de Los Ríos, Chile

Correspondence to: Heriberto Fernández Universidad Austral de Chile, Instituto de Microbiología Clínica, Edificio de Ciencias Biomédicas, Campus Isla Teja Valdivia, Región de Los Ríos, 5090000, Chile Tel: +56 $632214377,+56632293300$

E-mail: hfernand@uach.cl

Received: 16 May 2017

Accepted: 28 July 2017

\section{Occurrence and antimicrobial susceptibility of thermophilic Campylobacter species isolated from healthy children attending municipal care centers in Southern Ecuador}

\author{
Zorayda Toledo', Rosa Janneth Simaluiza', Xavier Astudillo', Heriberto \\ Fernández ${ }^{2}$
}

\section{ABSTRACT}

The prevalence and antimicrobial susceptibility of Campylobacter jejuni and C. coli strains in healthy, well-nourished children of middle socioeconomic level from Southern Ecuador were determined. Among the 127 children studied, 17 (13.4\%) harbored Campylobacter sp. corresponding to $C$. jejuni $(7.1 \%)$ and $C$. coli $(6.3 \%)$ with a higher concentration of $C$. jejuni among boys $(8.6 \%)$ and $C$. coli $(8.8 \%)$ among girls. $C$. jejuni showed high resistance to nalidixic acid and ciprofloxacin $(77.8 \%)$, but susceptibility to all other antimicrobials tested. C. coli strains showed resistance to more antibiotics than $C$. jejuni strains including resistance to nalidixic acid (75\%), ciprofloxacin (75\%), erythromycin (12.5\%) and ampicillin (28.6), but susceptible to gentamicin and amoxicillin/clavulanic acid.

KEYWORDS: Campylobacter. Healthy carriers. Children. Antimicrobials. Ecuador. Campylobacter jejuni, Campylobacter coli, Campylobacter resistance and susceptibility to antibiotics

Currently, the genus Campylobacter comprises 27 species and 12 subspecies. They are considered as ubiquitous bacteria frequently found in the intestinal tract of a wide range of animals, including birds, mammals and reptiles, which are also recognized as reservoir for these bacteria ${ }^{1-3}$.

Several Campylobacter species have been reported as infectious agents for humans in both, industrialized and developing countries, being the thermophilic Campylobacter species - C. jejuni, C. coli, C. lari and C. upsaliensis - most commonly associated with human infections, especially with acute infectious diarrhea. However, they could also produce extra-intestinal infections and severe complications leading to sequelae such as Guillain-Barré or Miller Fisher Syndromes ${ }^{4,5}$.

Campylobacter gastroenteritis is a major public health problem with increasing rates worldwide, being the most common cause of bacterial diarrhea in developed countries and the second or third cause in developing countries, particularly in South America $^{3,6,7}$. The available clinical, laboratory and epidemiological data have been produced mainly in developed countries, where national surveillance programs for campylobacteriosis exist ${ }^{8}$. In general, developing countries do not have this kind of programs or they are just implementing them, which does not allow reliable and conclusive epidemiological data ${ }^{9}$. On the other hand, in developing countries, Campylobacter is not routinely diagnosed as enteric pathogens, thus, their frequency in infant community-acquired diarrhea is commonly underestimated ${ }^{10}$.

Campylobacter isolation rates in diarrheic patients from developing countries 
range from 5 to $23 \% \%^{7,8}$. Isolation of Campylobacter from children without diarrhea in those countries seems to be a frequent epidemiological fact ${ }^{7,11}$ but it is not well-documented in many of them as to allow real epidemiological data. Moreover, in developing countries, Campylobacter is a common cause of diarrheal disease among children at risk for growth failure ${ }^{12}$.

Among children, Campylobacter infections are mainly responsible for digestive manifestations especially acute diarrhea and in a lesser extent, chronic or recurrent diarrhea. More rarely, immune-mediated complications (reactive arthritis and Gillain Barré syndrome) and extra intestinal infections like bacteremia can occur ${ }^{13,14}$.

Campylobacter gastroenteritis in humans is considered a zoonotic foodborne illness ${ }^{6,7}$. In the last years, over $40 \%$ of laboratory-confirmed Campylobacter strains were resistant to several antimicrobials, mainly to tetracyclines, quinolones and macrolides, limiting treatment options ${ }^{6,7}$. In developing countries, high resistance levels have been found among Campylobacter strains isolated from intestinal and extra-intestinal infections in children ${ }^{14-16}$.

The aim of this descriptive study, performed during five months, from May to September 2016, was to determine the occurrence and antimicrobial susceptibility of thermophilic Campylobacter species in healthy well-nourished children of middle socioeconomic level in Southern Ecuador.

Stool samples were obtained from each of 127 children who attended municipal day-care centers of Loja city ( $3^{\circ} 59^{\prime}$ Lat $S ; 79^{\circ} 12^{\prime}$ Long W). Children aged $1-16$ years with median age of 7.2 years, being 57 females and 70 males. Parents of all study participants provided written informed consent and the study was approved by the Ethics Committee of the Universidad Técnica Particular de Loja.

Once obtained, each stool sample was seeded into the semisolid TEM (transport enrichment medium) described by Fernández ${ }^{17}$ consisting of Brucella broth $28 \mathrm{~g}$, agar $1.5 \mathrm{~g}$, sodium metabisulphite $0.5 \mathrm{~g}$, ferrous sulfate $0.5 \mathrm{~g}$, sodium pyruvate $0.5 \mathrm{~g}$, trimethoprim $10 \mathrm{mg}$, rifampicin $15 \mathrm{mg}$, colistin 10,000 IU, amphotericin $10 \mathrm{mg}$ and defibrinated horse blood $30 \mathrm{~mL}$ (formula/L) and transported to the laboratory. Following an enrichment period of $24 \mathrm{~h}$ at $42{ }^{\circ} \mathrm{C}$ under microaerobic conditions obtained using generator envelopes (Oxoid), sample aliquots were seeded onto Butzler's medium plates that were incubated for $48 \mathrm{~h}$ under the same conditions described above. Suspected colonies were identified morphologically (Gram stain), biochemically (oxidase, catalase, sensitivity to nalidixic acid and cephalothin, hippurate and indoxyl acetate hydrolysis) and confirmed by the multiplex PCR test proposed by Yamazaki-Matsune et al. ${ }^{18}$. In brief, after extraction of genomic DNA, $5 \mu \mathrm{L}$ of template DNA were added to a mixture containing $2 \mu \mathrm{M}$ of each primer and $25 \mu \mathrm{L}$ of $2 \mathrm{x}$ Multiplex PCR Master Mix (QIAGEN, USA) adjusting final volume to $50 \mu \mathrm{L}$ with RNase-free $\mathrm{H}_{2} \mathrm{O}$. DNA amplification was performed in thermocycler (Eppendorf) using the following cycling conditions: one cycle of initial denaturation at $95^{\circ} \mathrm{C}$ for $15 \mathrm{~min}$., followed by 25 cycles of denaturation at $95{ }^{\circ} \mathrm{C}$ for $0.5 \mathrm{~min}$; annealing was done at $58^{\circ} \mathrm{C}$ for $1.5 \mathrm{~min}$ and extension at $72^{\circ} \mathrm{C}$ for $1 \mathrm{~min}$, ending with a final extension time at $72{ }^{\circ} \mathrm{C}$ for $7 \mathrm{~min}$. Reaction mixtures were analyzed by gel electrophoresis $(3 \% \mathrm{w} / \mathrm{v}$ agarose) stained with ethidium bromide and visualized under UV transilluminator.

Susceptibility to ampicillin $(10 \mu \mathrm{g})$, amoxicillin/clavulanic acid $(20 / 10 \mu \mathrm{g})$, erythromycin $(15 \mu \mathrm{g})$, ciprofloxacin $(5 \mu \mathrm{g})$, nalidixic acid $(30 \mu \mathrm{g})$, tetracycline $(30 \mu \mathrm{g})$ and gentamycin $(10 \mu \mathrm{g})$ was determined by the disk diffusion method following the 2014 recommendations of The European Committee on Antimicrobial Susceptibility Testing-EUCAST and the Antibiogram Committee of the French Microbiology Society ${ }^{19}$ using Müller-Hinton agar supplemented with 5\% horse blood and $20 \mathrm{mg} / \mathrm{L}$ of $\beta$-NAD. Inocula were prepared suspending several well-isolated colonies of each strain in sterile saline buffer $(\mathrm{NaCl} 0.9 \%)$ until obtaining a turbidity equal to $0.5 \mathrm{McFarland}$ nephelometer. Suspensions were seeded on the plates using soaked swabs and after allowing to dry, antibiotic discs were placed on the plates. After $24 \mathrm{~h}$ of incubation under microaerobic conditions at $37^{\circ} \mathrm{C}$, diameters of the inhibition zones were measured to establish resistance (R) and susceptibility (S) in accordance with the breakpoints proposed by EUCAST (ampicillin $\mathrm{R}<14 \mathrm{~mm}$, $\mathrm{S}=19 \mathrm{~mm}$; amoxicillin/clavulanic acid $\mathrm{R}<14 \mathrm{~mm}$, $\mathrm{S}=19 \mathrm{~mm}$; erythromycin $\mathrm{R}<20 \mathrm{~mm}, \mathrm{~S}=20 \mathrm{~mm}$; ciprofloxacin $\mathrm{R}<26 \mathrm{~mm}, \mathrm{~S}=26 \mathrm{~mm}$; nalidixic acid $\mathrm{R}<26 \mathrm{~mm}, \mathrm{~S}=26 \mathrm{~mm}$; tetracycline $\mathrm{R}<30 \mathrm{~mm}, \mathrm{~S}=30 \mathrm{~mm}$; and gentamycin $\mathrm{R}<17 \mathrm{~mm}, \mathrm{~S}=17 \mathrm{~mm}$ ). Campylobacter jejuni ATCC 33560 strain was used as quality control.

Of the 127 children studied, 17 (13.4\%) harbored Campylobacter sp. corresponding 9 (12.9\%) to boys and $8(14.0 \%)$ to girls. Asymptomatic excretion of Campylobacter species is commonly reported among children from developing countries ${ }^{7}$. In South America, frequencies ranging from $4.9 \%$ to $13.8 \%$ have been reported $^{7}$. The prevalence of Campylobacter isolation rate found in our study (13.4\%) was significantly higher to the $6 \%$ (C. jejuni $4 \%$; C. coli $2 \%$ ) reported in a recent survey conducted in the Ecuadorian capital, city of Quito, among children without diarrhea ${ }^{20}$. This asymptomatic excretion is an epidemiological feature commonly observed in developing countries ${ }^{7}$, probably associated with poor sanitation conditions and frequent contact with domestic animals considered as reservoirs ${ }^{6,7,21}$. Furthermore, the high 
Table 1 - Distribution of Campylobacter by sex

\begin{tabular}{lcccc}
\hline \multirow{2}{*}{ Sex } & Number Examined & $\begin{array}{c}\text { Positive samples } \\
\text { Number (\%) }\end{array}$ & & \multicolumn{2}{c}{$\begin{array}{c}\text { Species isolated } \\
\text { Number (\%) }\end{array}$} \\
\cline { 4 - 5 } Male $^{*}$ & 70 & $9(12.9)$ & C. jejuni & C. coli \\
Female* $_{\text {Total }}$ & 57 & $8(14.0)$ & $3(8.6 \%)$ & $5(8.8 \%)$ \\
\hline
\end{tabular}

${ }^{*} \mathrm{P}>0.005$

Table 2 - Distribution of Campylobacter by age

\begin{tabular}{lcccc}
\hline Age (months) & Number Examined & \% Positive & C. jejuni & C. coli \\
\hline $0-24$ & 28 & 7.1 & 0 & 2 \\
$25-60$ & 73 & 12.3 & 4 & 5 \\
$>60$ & 26 & 23.1 & 5 & 1 \\
\hline Total & 127 & 13.4 & 9 & 8 \\
\hline
\end{tabular}

Table 3 - Antimicrobial resistance of C. jejuniand C. coli isolated in Loja city, Ecuador

\begin{tabular}{lcc}
\hline Antimicrobial agent & $\begin{array}{c}\text { C. jejuni } \mathrm{N}=9 \\
\%\end{array}$ & $\begin{array}{c}\text { C. coli } \mathrm{N}=8 \\
\%\end{array}$ \\
\hline Nalidixic acid & 77.8 & 75.0 \\
Ciprofloxacin & 77.8 & 75.0 \\
Erythromycin & 0 & 12.5 \\
Gentamicin & 0 & 0 \\
Ampicillin & 0 & 28.6 \\
Amoxicillin/ & & 0 \\
clavulanic acid & 0 & 50.0 \\
Tetracycline & 60.0 & \\
\hline
\end{tabular}

prevalence of Campylobacter in asymptomatic children may be related to the development of protective immunity due to exposure in early life ${ }^{3}$.

In Loja region, it was demonstrated that dogs can be a common source of environmental contamination for C. jejuni and C. coli ${ }^{22}$. On the other hand, holding small backyard for raising poultry flocks and guinea pigs are popular among Ecuadorian people as meat source. High Campylobacter isolation rates have been found among these two types of meat source ${ }^{23,24}$.

In this study, the isolation frequencies of both species, C. jejuni $(7.1 \%)$ and C. coli $(6.3 \%)$, were similar as it was also the global Campylobacter isolation rates among males and females $(\mathrm{P}>0.005)$. Although it is noteworthy that there was a higher concentration of $C$. jejuni among boys $(8.6 \%)$ and $C$. coli $(8.8 \%)$ among girls. Reasons for this are unknown and as far as we know, this particular species distribution related to gender has not been described. Some risk factors, like rurality and contact with chickens or chicken meat, have been associated with $C$. coli infection in developed countries ${ }^{25}$. Further epidemiological studies are necessary in developing countries to explain this issue as well as the causes responsible for its occurrence.

In industrialized countries, infection is more prevalent in children under four years old $^{3}$ whereas, in developing countries, it is in children under two years old ${ }^{7,26}$. Despite the fact that asymptomatic colonization with Campylobacter is a common feature reported in developing countries ${ }^{7}$, little is known about their age distribution. In a Peruvian survey ${ }^{26}$, asymptomatic carriers were the most frequent among children $<1$ year $(16.7 \%)$ declining up to six years old to $3.8 \%$. The opposite was observed in our study where the lowest isolation rate $(7.1 \%)$ was found among children $<2$ years old, occurring an increase in the frequency of isolation as age rises (up to five years old $12.3 \%$; over five years old $23.1 \%$ ). Further studies are needed to explain this age distribution.

All the $C$. jejuni strains were susceptible to erythromycin, gentamicin, ampicillin and amoxicillin/clavulanic acid, but $77.8 \%$ of the isolates were resistant to nalidixic acid and ciprofloxacin. C. coli strains were resistant to more antimicrobials than $C$. jejuni strains. Resistant strains were found for nalidixic acid $(75 \%)$, ciprofloxacin $(75 \%)$, erythromycin $(12.5 \%)$ and ampicillin $(28.7 \%)$, but all were susceptible to gentamicin and amoxicillin/clavulanic acid. EUCAST has not proposed breakpoints for nalidixic acid. Therefore, we homologate the EUCAST breakpoints of ciprofloxacin to define resistance and susceptibility to nalidixic acid. A good correlation among nalidixic acidresistant and ciprofloxacin-resistant strains was observed, 
indicating that nalidixic acid is a good quinolone resistance indicator, therefore, useful to establish surveillance of resistance to these antimicrobials. High resistance to ciprofloxacin was previously reported in Loja city in C. jejuni and C. coli strains isolated from dog feces ${ }^{22}$, chicken $^{23}$ and chicken livers for human consumption ${ }^{27}$, thus suggesting that this resistance could also be found with high frequency among strains isolated from human beings. The three ampicillin-resistant strains were susceptible to amoxicillin/clavulanic acid indicating that these resistant strains were beta-lactamase producers, as it has been observed in other Latin American countries ${ }^{28}$.

\section{ACKNOWLEDGMENTS}

This work was supported by Project PRO_CCSAL_1077.

\section{REFERENCES}

1. LPSN. List of prokaryotic names with standing in nomenclature: Genus Campylobacter. [cited 2016 May 02]. Available from: http://www.bacterio.net/campylobacter.html

2. Piccirillo A, Niero G, Calleros L, Pérez R, Naya H, Iraola G. Campylobacter geochelonis sp. nov. isolated from the western Hermann's tortoise (Testudo hermanni hermanni). Int J Syst Evol Microbiol. 2016;66:3468-76.

3. Kaakoush NO, Castaño-Rodríguez N, Mitchell HM, Man SM. Global epidemiology of Campylobacter infection. Clin Microbiol Rev. 2015;28:687-720.

4. Man SM. The clinical importance of emerging Campylobacter species. Nat Rev Gastroenterol Hepatol. 2011;8:669-85.

5. Lastovica AJ. Non-jejuni/coli Campylobacter species and related organisms in poultry, and their relevance in human and animal disease. In: Fonseca BB, Fernández H, Rossi D, editors. Campylobacter spp. and related organisms in poultry: pathogen-host interactions, diagnosis and epidemiology. Geneve: Springer; 2016. p.185-206.

6. World Health Organization. The global view of campylobacteriosis: report of an expert consultation, Utrecht, Netherlands, 9-11 July 2012. Geneva: WHO; 2013.

7. Fernández H. Campylobacter y campylobacteriosis: una mirada desde América del Sur. Rev Per Med Exp Salud Publ. 2011;28:121-7.

8. Epps SV, Harvey RB, Hume ME, Phillips TD, Anderson RC, Nisbet DJ. Foodborne Campylobacter: infections, metabolism, pathogenesis and reservoirs. Int J Environ Res Public Health. 2013;10:6292-304.

9. Porte L, Varela C, Haecker T, Morales S, Weitzel T. Impact of changing from staining to culture techniques on detection rates of Campylobacter spp. in routine stool samples in Chile. BMC Infect Dis. 2016;16:196.
10. Varela G, Batthyány L, Bianco MN, Pérez W, Pardo L, Algorta $\mathrm{G}$, et al. Enteropathogens associated with acute diarrhea in children from households with high socioeconomic level in Uruguay. Int J Microbiol. 2015;2015:592953.

11. Fernández H, Vera F, Villanueva MP, García A. Occurrence of Campylobacter species in healthy well-nourished and malnourished children. Braz J Microbiol. 2008;39:56-8.

12. Lee G, Pan W, Peñataro Yori P, Paredes Olortegui M, Tilley D, Gregory M, et al. Symptomatic and asymptomatic Campylobacter infections associated with reduced growth in Peruvian children. PLoS Negl Trop Dis. 2013;7:e2036.

13. Lehours P, Aladjidi N, Sarlangue J, Mégraud F. Infections à Campylobacter chez l'enfant. Arch Pediatr. 2012;19:629-34.

14. Anvarinejad M, Amin Shahidi M, Pouladfar GR, Dehyadegari MA, Mardaneh J. Campylobacter jejuni bacteremia in a patient with acute lymphocytic leukemia. Iran Red Crescent Med J. 2016;18:e23992.

15. McCrackin MA, Helke KL, Galloway AM, Poole AZ, Salgado $\mathrm{CD}$, Marriott BP. Effect of antimicrobial use in agricultural animals on drug-resistant foodborne campylobacteriosis in humans: a systematic literature review. Crit Rev Food Sci Nutr. 2016;56: 2115-32.

16. Pan H, Ge Y, Xu H, Zhang J, Kuang D, Yang X, et al. Molecular characterization, antimicrobial resistance and Caco-2 cell invasion potential of Campylobacter jejuni/coli from young children with diarrhea. Pediatr Infect Dis J. 2016;35:330-4.

17. Fernández H. Increase of Campylobacter isolation rates using an enrichment medium. Rev Microbiol. 1992;23:5-7.

18. Yamazaki-Matsune W, Taguchi M, Seto K, Kawahara R, Kawatsu K, Kumeda Y, et al. Development of a multiplex PCR assay for identification of Campylobacter coli, Campylobacter fetus, Campylobacter hyointestinalis subsp. hyointestinalis, Campylobacter jejuni, Campylobacter lari and Campylobacter upsaliensis. J Med Microbiol. 2007;56:1467-73.

19. Société Française de Microbiologie. Comité de l'Antibiogramme. Recommandations 2014. Paris: Société Française de Microbiologie; 2014. [cited 2017 July 28]. Available from: http://www.sfm-microbiologie.org/UserFiles/files/casfm/ CASFM_EUCAST_V1_0_2014(1).pdf

20. Vasco G, Trueba G, Atherton R, Calvopiña M, Cevallos W, Andrade T, et al. Identifying etiological agents causing diarrhea in low income Ecuadorian communities. Am J Trop Med Hyg. 2014;91:563-9.

21. Fernández H, Kahler K, Salazar R, Ríos M. Prevalence of thermotolerant species of Campylobacter and their biotypes in children and domestic birds and dogs in Southern Chile. Rev Inst Med Trop Sao Paulo. 1994;36:433-6.

22. Toledo Z, Simaluiza RJ, Ochoa S, Fernández H. Occurrence and antimicrobial susceptibility of Campylobacter jejuni and C. coli in dog feces from public parks in Southern Ecuador. Acta Scient Vet. 2015;43:1284. 
23. Ochoa S, Simaluiza RJ, Toledo Z, Fernández H. Frequency and antimicrobial behaviour of thermophilic Campylobacter species isolated from Ecuadorian backyard chickens. Arch Med Vet. 2016;48:311-4.

24. Graham JP, Vasco K, Trueba G. Hyperendemic Campylobacter jejuni in guinea pigs (Cavia porcellus) raised for food in a semi-rural community of Quito, Ecuador. Environ Microbiol Rep. 2016;8:382-7.

25. Roux F, Sproston E, Rotariu O, MacRae M, Sheppard SK, Bessell $\mathrm{P}$, et al. Elucidating the aetiology of human Campylobacter coli infections. PLoS One. 2013;8:e64504.
26. Oberhelman RA, Gilman RH, Sheen P, Cordova J, Taylor DN, Zimic M, et al. Campylobacter transmission in a Peruvian shantytown: a longitudinal study using strain typing of Campylobacter isolates from chickens and humans in household clusters. J Infect Dis. 2003;187:260-9.

27. Simaluiza RJ, Toledo Z, Ochoa S, Fernández H. The prevalence and antimicrobial resistance of Campylobacter jejuni and Campylobacter coli in chicken livers used for human consumption in Ecuador. J Anim Vet Adv. 2015;14:6-9.

28. Fernández H, Oval A. Occurrence of Campylobacter jejuni and Campylobacter coli biotypes and antimicrobial susceptibility in healthy dogs in Southern Chile. Acta Scient Vet. 2013;41:1100. 